\title{
Ethical Conduct in a provincial government department in South Africa
}

\author{
Keneilwe Rispah Moloisi ${ }^{1}$, Ricky Munyaradzi Mukonza² \\ Tshwane University of Technology, South Africa \\ Department of Public Management, Tshwane University of Technology, South Africa
}

\begin{abstract}
Public officials have a greater responsibility to account to citizens, therefore they are expected to execute their duties with professionalism, honesty, courtesy and integrity and they are expected to refrain from unethical conduct that cripple the moral fibre of society. It is imperative for government officials to conduct themselves ethically in executing their daily duties and again it is of great importance to annotate that professional ethics in public administration is vital to ensure moral values, obligation, principles, attitudes and norms governing public functionaries. The main aim of this study was to examine ethical conduct in the Limpopo Provincial Government, Department of Agriculture and Rural Development as a case study. The proposed study was used to make suggestions on how to rebuild government 's integrity and also to address ethical challenges that South Africa's public service is facing. The mixed research methodology was utilised, with unstructured interviews and structured (selfadministered) questionnaires as tools to collect primary data. A combination of probability and non-probability sampling methods were employed in selecting sample elements from the population. Furthermore, both qualitative and quantitative methods of data analysis were used for the purpose of this study. Based on the study findings although Limpopo Provincial Government, Department of Agriculture and Rural Development's officials were ethically behaving in their dealings with the public, not all the clients and community members were satisfied about their conduct. The evidence collected indicated that the citizens does not know the code of conduct for the department. Consequently, the paper recommends that the department should develop their own clear policies, procedures, code of conduct towards ethical conduct of officials.
\end{abstract}

Keywords: Ethical Conduct, Public Officials, Unethical Conduct, Public Service, Code of Conduct. 